\title{
Estimating snowshoe hare population density from pellet plots: a further evaluation
}

\author{
Charles J. Krebs, Rudy Boonstra, Vilis Nams, Mark O'Donoghue, \\ Karen E. Hodges, and Stan Boutin
}

\begin{abstract}
We counted fecal pellets of snowshoe hares (Lepus americanus) once a year in 10 areas in the southwestern Yukon from 1987 to 1996 . Pellets in eighty $0.155-\mathrm{m}^{2}$ quadrats were counted and cleared each June on all areas, and we correlated these counts with estimates of absolute hare density obtained by intensive mark-recapture methods in the same areas. There is a strong relationship between pellet counts and population density $(r=0.76)$, and we present a predictive log-log regression to quantify this relationship, which improves on our previously published 1987 regression, particularly at low hare densities. The precision of density estimates can be improved most easily by increasing the number of sets of quadrats in an area (one set $=80$ plots), rather than increasing the number of plots counted within one set. The most important question remaining concerns the generality of this relationship for snowshoe hares living in other habitats in the eastern and southern portions of their geographic range.

Résumé : Nous avons compté les boulettes fécales de Lièvres d'Amérique (Lepus americanus) une fois l'an en 10 zones du sud-ouest du Yukon, de 1987 à 1996. Les boulettes ont été comptées chaque juin, puis retirées, dans quatre-vingt quadrats de $0,155 \mathrm{~m}^{2}$ dans chacune des zones; par la suite, ces nombres ont été mis en corrélation avec des estimations de la densité absolue des lièvres obtenues par des méthodes intensives de capture-recapture dans les mêmes zones. Il y a une forte corrélation entre le nombre de boulettes et la densité de la population $(r=0,76)$ et nous présentons ici une régression log-log prédictive pour quantifier cette relation, ce qui rend plus robuste la régression que nous avons publiée en 1987, particulièrement lorsque la densité des lièvres est faible. La précision des estimations de la densité peut être raffinée davantage en augmentant le nombre d'ensembles de quadrats dans une région $(1$ ensemble $=80$ parcelles), plutôt que le nombre de parcelles dans chaque ensemble. Il reste à déterminer à quel point cette relation est généralisée chez les lièvres qui vivent dans d'autres habitats dans les portions est et sud de leur répartition.
\end{abstract}

[Traduit par la Rédaction]

\section{Introduction}

The snowshoe hare (Lepus americanus) is a keystone herbivore in the boreal forests of Canada, Alaska, and parts of the United States bordering southern Canada. Estimating snowshoe hare population density is labor-intensive if markrecapture methods are utilized. Consequently, from 1977 to 1983, we counted fecal pellets of hares on small quadrats in

Received May 9, 2000. Accepted September 18, 2000.

Published on the NRC Research Press website on December 6, 2000.

C.J. Krebs. ${ }^{1}$ Department of Zoology, University of British Columbia, Vancouver, BC V6T 1Z4, Canada.

R. Boonstra. Division of Life Sciences, University of Toronto at Scarborough, 1265 Military Trail, Scarborough, ON M1C 1A4, Canada.

V. Nams. Department of Environmental Sciences, Nova Scotia Agricultural College, Truro, NS B2N 5E3, Canada. M. O'Donoghue. Department of Renewable Resources, Fish and Wildlife Branch, P.O. Box 310, Mayo, YT Y0B 1M0, Canada.

K.E. Hodges. Center for Biodiversity Research, University of British Columbia, Vancouver, BC V6T 1Z4, Canada.

S. Boutin. Department of Biological Sciences, University of Alberta, Edmonton, AB T6G 2E9, Canada.

${ }^{1}$ Author to whom all correspondence should be addressed (e-mail: krebs@zoology.ubc.ca). six areas near Kluane Lake, Yukon, in order to calibrate pellet counts with absolute population density (Krebs et al. 1987). The resulting regression had relatively narrow confidence limits and we proposed that hare densities could be quickly estimated by counting fecal pellets.

The use of any indirect method raises the question of its spatial and temporal generality. The listing of the Canada lynx (Lynx canadensis) as a threatened species in the United States has stimulated much research on snowshoe hares as potential prey of lynx in the western states (Ruggiero et al. 2000), and pellet plots may become an attractive tool for estimating hare densities across a wide region. At present we do not know if these regressions are valid for snowshoe hares outside of the Kluane boreal forest region, particularly in such areas as the southern boreal and montane forests of Washington, Idaho, Montana, Wyoming, and Colorado (Hodges 2000). This paper addresses the question of temporal generality: how well does the predictive regression obtained from 1977-1983 describe data collected on a larger scale from 1986 to 1996 in the same region of the Yukon?

\section{Methods}

We established 80 sampling quadrats in each of 10 snowshoe hare livetrapping areas in the Kluane region of the Yukon $\left(61^{\circ} \mathrm{N}\right.$, $\left.138^{\circ} \mathrm{W}\right)$. Each quadrat was $5.08 \times 305 \mathrm{~cm}(2 \mathrm{in} . \times 10 \mathrm{ft})$ in area. In earlier work (Krebs et al. 1987) it had been determined that these long, thin quadrats were optimal for sampling fecal pellets of hares, 
Fig. 1. Relationship between the mean number of fecal pellets from snowshoe hares (Lepus americanus) on $0.155-\mathrm{m}^{2}$ quadrats (log scale) and the estimated population density of hares (log scale) in 10 areas at Kluane Lake, Yukon Territory, 1986-1996. Fecal pellets accumulated over 1 year were counted in June, and snowshoe hare density was estimated by mark-recapture over the same time period. The uncorrected (broken) line is the simple linear regression; the corrected line is bias-corrected using the method of Sprugel (1983).

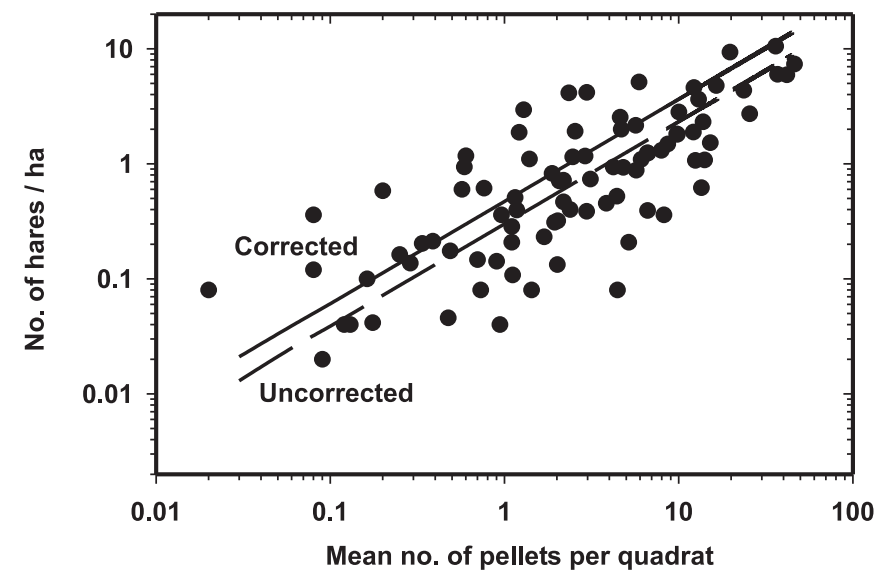

and we confirmed these results by another unpublished study in 1989. We sampled livetrapping areas systematically with 20 quadrats spaced $30 \mathrm{~m}$ apart down each of four parallel lines spaced $120 \mathrm{~m}$ apart, and placed permanent markers at the ends and in the centre of each quadrat so that they could be relocated exactly in subsequent years. We cleared all hare pellets on these quadrats during the summer of 1986, and then counted fecal pellets once each year in June from 1987 to 1996. The data available are thus the number of fecal pellets that had accumulated over 1 year on each quadrat. After the pellets were counted, each quadrat was again cleared so that each year we counted pellets produced only during the previous 12 months. This removal is critical in the boreal-forest environment because hare fecal pellets may last more than 20 years before disintegrating.

We then compared these pellet counts with snowshoe hare population density estimates obtained by mark-recapture techniques. Both Jolly-Seber estimates and CAPTURE estimates (Krebs 1999) were used to estimate hare densities on our trapping grids, which effectively covered 60 ha, including a boundary strip. The population-density estimates were averaged from June 1 in year $t-1$ to May 31 in year $t$ and were plotted against the mean pellet count in year $t$. In a few cases we did not livetrap a sampling grid in a particular year, so a population estimate was not available for our analysis. All told, 85 data points were collected for analysis, with hare densities ranging from 0.02 to $10.5 /$ ha. Some of these data were collected from grids subjected to experimental treatments like food addition (Krebs et al. 1995).

\section{Results}

Mean pellet counts ranged from 0.02 to 46.2 per quadrat and mean snowshoe hare population density from 0.02 to $10.5 /$ ha in the 85 samples (Fig. 1). Because the variance increased with the mean, a log transformation was applied to both the $X$ variable (pellet counts) and the $Y$ variable (estimated density). Because there are measurement errors in both the $X$ and $Y$ variables, we used the functional regression
Fig. 2. Lower 95\% confidence limits for the prediction of snowshoe hare density from pellet counts on $0.155-\mathrm{m}^{2}$ quadrats at Kluane Lake, Yukon Territory. The uppermost solid line is the predicted mean value (corrected for $\log -\log$ regression). Two lower confidence lines are shown, the lower one for one sample of 80 quadrats and the upper one for three samples of 80 quadrats. The confidence limits for prediction can be appreciably reduced by sampling three sets of 80 quadrats per site rather than one set, and this is what we recommend.

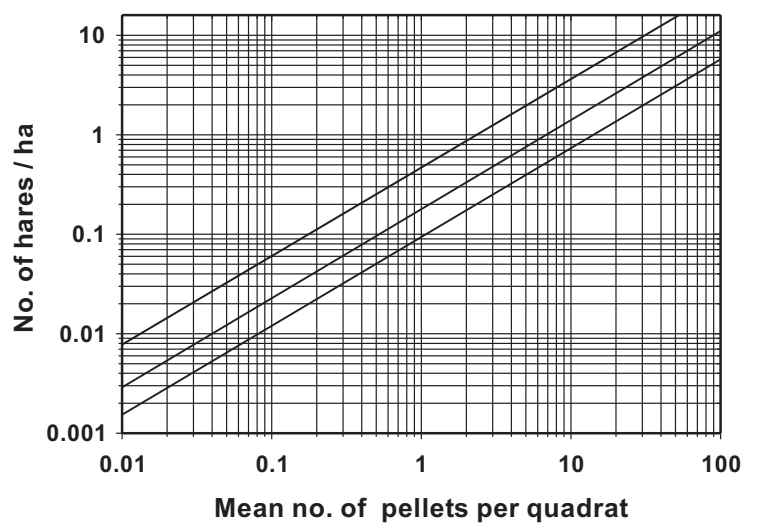

(Ricker 1984; Sokal and Rohlf 1995, p. 541) to describe these data. The functional regression is given by

$$
\begin{aligned}
& \log _{\mathrm{e}} \text { (population density) }= \\
& -1.203+0.889 \log _{\mathrm{e}} \text { (mean no. of pellets) }
\end{aligned}
$$

The correlation coefficient is 0.76 and the standard error of the slope is 0.062741. Log-log regressions produce biased predictions because of the transformation, and to correct for this bias Sprugel (1983) recommended multiplying the final estimates (number of hares per hectare) by a correction factor, which for this regression is given by

$$
\text { Correction factor }=\mathrm{e}^{(V / 2)}=\mathrm{e}^{(0.89836 / 2)}=1.567
$$

where $V$ is the variance about the $\log _{\mathrm{e}}-\log _{\mathrm{e}}$ regression, 0.89836 .

This regression is improved over the previous regression shown in Fig. 1 in Krebs et al. (1987), particularly at low pellet counts. The 1987 linear regression underestimates hare densities by about $8-12 \%$ compared with the present regression for densities above 1.5 hares/ha, but overestimates them dramatically at low hare densities (e.g., the 1987 regression gives a $45 \%$ overestimate of hare densities at 0.5 hares/ha compared with the present regression). Because many of the conservation issues about lynx involve low-density hare populations, this $\log -\log$ regression equation represents a significant improvement over our previous equation.

Figure 2 shows lower 95\% confidence limits for the prediction of hare densities from pellet counts. Two alternatives are illustrated, one with a single set of 80 quadrats counted per site and a second with three sets of 80 quadrats counted. Because in many cases the biologically significant question is how low the hare density might be, given a particular pellet count, we emphasize the lower confidence belt. As with any $\log -\log$ regression, the upper confidence limits are often very large and ecologically unrealistic. For example, for 5 pellets per quadrat, the predicted density would be 2 hares/ha, with $90 \%$ confidence limits of 0.4 to 10 hares/ha for one set 
Fig. 3. Relationship between the mean and variance of snowshoe hare pellet counts on eighty $0.155-\mathrm{m}^{2}$ quadrats on 10 sites sampled annually from 1987 to 1996 at Kluane Lake, Yukon Territory. The solid line is the functional regression $(r=0.978)$.

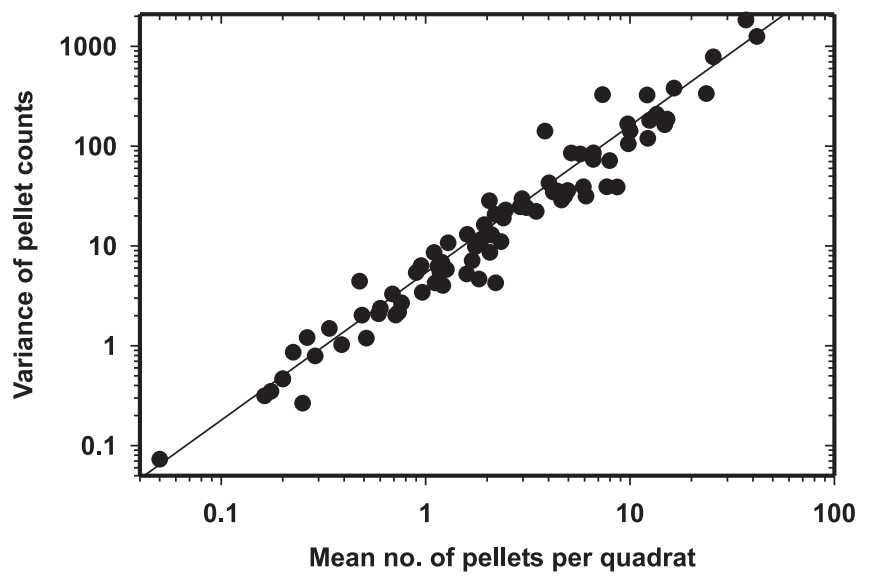

of 80 quadrats per site. But natural populations of hares never exceed about 10/ha, and these upper limits are often of little biological relevance.

Confidence limits for population density can be narrowed significantly by counting more than one set of 80 quadrats per site. For the above example of 5 pellets per quadrat, the $90 \%$ confidence belt would be $0.8-5$ hares/ha if three sets were counted, and would be reduced still further to 14 hares/ha if five sets of quadrats were counted. A lower density of 1 pellet per quadrat would produce a mean density estimate of 0.5 hares/ha and corresponding limits of $0.1-2.3,0.2-1.2$, and $0.2-1.0$ hares/ha, respectively.

The variance in these estimates is partly produced by the clumped pattern of snowshoe hare pellets, so the variance always exceeds the mean. Figure 3 illustrates the relationship between the mean and variance for the pellet counts, which fits Taylor's Power Law (Krebs 1999, p. 329) with the regression

$$
\begin{aligned}
& \log _{\mathrm{e}}(\text { variance })= \\
& \left.1.5860+1.4238 \log _{\mathrm{e}} \text { (mean no. of pellets }\right)
\end{aligned}
$$

with $r=0.978$ and $n=85$. To keep the precision of the estimates at a relative level of $\pm 40 \%$ of the mean density would require about 10 sets of samples per area. By contrast, to keep the precision constant at an absolute density level, e.g., \pm 0.3 hares/ha, would require many more samples at high hare densities than at low densities. Figure 4 illustrates the major part of the uncertainty, that associated with estimating the mean number of pellets per quadrat. Because these quadrat counts are negative-binomially distributed, with the variance increasing with the mean, at low pellet densities counting more quadrats dramatically improves the precision. We counted sets of 80 quadrats to generate the regression in Fig. 1. Figure 4 shows that it would not be wise to reduce this basic unit of sampling below 80 .

\section{Discussion}

The major difference between the 1987 hare density - pellet count regression and the revised one presented in Fig. 1 is in the spread of the data. While for the 1977-1983 data, $r=$
Fig. 4. Relationship between the mean number of fecal pellets and the predicted width of the confidence interval of the mean number of pellets for sample sizes of $30,50,80,200$, and 400 quadrats per site. On the $y$ axis, the width of the confidence interval divided by the mean number of pellets is expressed as a percentage. The relationship between the mean and variance in Fig. 3 is assumed. To attain high precision in calculating the mean number of pellets at low densities requires a large sample of quadrats to be counted. A mean of 1 pellet per quadrat translates to about 0.5 hares/ha.

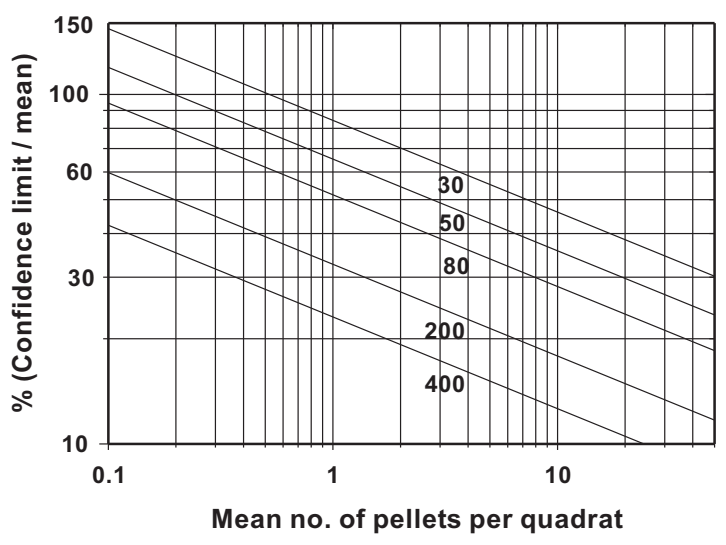

0.90 in $\log -\log$ space, the 1986-1996 data showed a reduction to $r=0.76$. The slope and intercept of the earlier regression are not significantly different from the more extensive recent data. The first point we emphasize is that the relationship outlined in 1987 is repeatable in time.

It is not yet known how repeatable these patterns are in space, and we encourage further tests of the robustness of this regression in other habitats. In particular, these relationships have been used in the western states to estimate hare densities in relation to the possibility of relocating Canada lynx into areas like Colorado. We strongly recommend confirming these regressions before using them to make management decisions.

The scatter shown in Fig. 1 may be implicit in the biological system. Density of snowshoe hares often changes significantly over a year, increasing up to 3 -fold in the increase phase of the 10-year cycle or declining by $90 \%$ in the decline phase (Hodges 2000). Because we are averaging population density over a 1-year interval, some variation is added to these regressions, depending on the phase in the cycle, as well as by the accuracy of hare-population estimates. A second source of variation is the edge effect of counting pellets on long, thin quadrats. All people counting were instructed concerning the importance of strictly defining the quadrat edge, but some individual variability persisted. A third source of variation arose from the fact that some pellets were either kicked into or out of the quadrats by animals moving through the area over the year. Older pellets could usually be distinguished because they have a brown core rather than a green one. A large area around the permanent quadrats was cleared each June to reduce this potential problem, which proved, however, to be only a minor source of variation.

The key methodological question that arises from this approach to estimating snowshoe hare density is how to obtain the narrowest confidence limits for the estimated hare density. The only approach available if Fig. 1 is to be used for 
estimation is to increase the number of quadrat sets per site. For example, Fig. 2 illustrates the improvement that can be achieved with three sets of 80 quadrats per site compared with one set of 80 quadrats. In the longer term, if this regression approach is to be developed for a new area, we recommend a four-step approach: (1) Find the optimum size and shape of quadrat for the new area. There is no reason to assume that the size and shape of the quadrats which we used will be optimal in all habitats. Krebs (1999, p. 105) discussed methods for determining the optimum size and shape of quadrats. (2) Determine the relationship between the mean and variance for the samples, and use this relationship to estimate the sample size needed to obtain a precise estimate of the mean number of pellets per site via two-stage sampling. We suspect that the scatter in Fig. 1 would have been greatly reduced if we had adopted this approach rather than using a fixed sample size. (3) Estimate the density of hares by markrecapture or other methods. Pollock et al. (1990) provide guidelines on estimating density. (4) Estimate the functional regression between hare density and pellet counts for the new area. Sokal and Rohlf (1995, p. 544) discuss this regression approach.

There are two estimates available of the fecal pellet production rates of snowshoe hares (Hodges 1999) that provide us with an approximate but independent way to check the validity of the regression in Fig. 1 . Hares produced $579 \pm 16$ (mean \pm SE) pellets per day in the field and $456 \pm 9$ per day in the laboratory (Hodges 1999). The slope of the line in Fig. 1 is not significantly different from 1.0, therefore we can ask what the fecal-pellet count would be if one hare lived on 1 ha for 1 year (i.e., a hare density of $1 /$ ha), producing 579 pellets per day and scattering them at random. The answer should be 3.3 pellets per $0.155-\mathrm{m}^{2}$ quadrat, on average. If the hare produced 456 pellets per day, there should be 2.6 pellets per quadrat, on average. The regression in Fig. 1 predicts 2.5 pellets per quadrat, slightly fewer than pelletproduction data suggest. Alternatively, if we accept the pelletproduction rate as correct, we could suggest that the regression in Fig. 1 overestimates hare density by about $30 \%$. Whatever the case, there is substantial agreement between these two estimates, given the variance shown in Fig. 1. To enhance this method, the key now is to find out if these relationships hold for hare populations in other regions.

Finally, we caution against using the predictive equation for hare densities reported in Slough and Mowat (1996, p. 948) because it contains typographical errors. For those interested, an EXCEL file is available from the senior author that will compute the correct estimates as shown in Fig. 1.

We do not know why the predictive regression for 19861996 in Fig. 1 has more scatter than the one obtained for 1977-1983. The main difference was that counting was done by only a few selected observers from 1977 to 1983, while many more individuals participated between 1986 and 1996.
A second difference was that the livetrapping areas were four times as large in 1986-1996 as in 1977-1983, so there would be more habitat variability in the grids used in the later study. Whatever the cause, the main result is that the relationship between the mean number of pellets and the variance of these counts (Fig. 3) is displaced upward in the 1986-1996 data compared with the equivalent regression for 1977-1983. For a given pellet count, there is more variance in the 1986-1996 data, and this is the main component adding noise to the predictive regression in Fig. 1.

\section{Acknowledgements}

We thank Cathy Doyle, Sabine Schweiger, Jocylyn McDowell, and many undergraduate assistants who have over the 10 years of study counted pellets in many quadrats. Financial support was provided by a Collaborative Special Project of the Natural Sciences and Engineering Research Council of Canada. The support of the Arctic Institute Kluane Lake Base Station was essential to this research, and we thank Andy Williams, who provided technical assistance.

\section{References}

Hodges, K.E. 1999. Proximate factors affecting snowshoe hare movements during a cyclic population low phase. Ecoscience, 6: 487-496.

Hodges, K.E. 2000. Ecology of snowshoe hares in southern boreal and montane forests. In Ecology and conservation of lynx in the United States. Edited by L.F. Ruggiero, K.B. Aubry, S.W. Buskirk, G.M. Koehler, C.J. Krebs, K.S. McKelvey, and J.R. Squires. University Press of Colorado, Denver. pp. 163-206.

Krebs, C.J. 1999. Ecological methodology. Addison Wesley Longman Inc., Menlo Park, Calif.

Krebs, C.J., Gilbert, B.S., Boutin, S., and Boonstra, R. 1987. Estimation of snowshoe hare population density from turd transects. Can. J. Zool. 65: 565-567.

Krebs, C.J., Boutin, S., Boonstra, R., Sinclair, A.R.E., Smith, J.N.M., Dale, M.R.T., Martin, K., and Turkington, R. 1995. Impact of food and predation on the snowshoe hare cycle. Science (Washington, D.C.), 269: 1112-1115.

Pollock, K.H., Nichols, J.D., Brownie, C., and Hines, J.E. 1990. Statistical inference for capture-recapture experiments. Wildl. Monogr. No. 107. pp. 1-97.

Ricker, W.E. 1984. Computation and uses of central trend lines. Can. J. Zool. 62: 1897-1905.

Ruggiero, L.F., Aubry, K.B., Buskirk, S.W., Koehler, G.M., Krebs, C.J., McKelvey, K.S., and Squires, J.R. (Editors). 2000. Ecology and conservation of lynx in the United States. University Press of Colorado, Denver, Colorado.

Slough, B.G., and Mowat, G. 1996. Lynx population dynamics in an untrapped refugium. J. Wildl. Manag. 60: 946-961.

Sokal, R.R., and Rohlf, F.J. 1995. Biometry. 3rd ed. W.H. Freeman and Co., New York.

Sprugel, D.G. 1983. Correcting for bias in log-transformed allometric equations. Ecology, 64: 209-210. 